\title{
The AMP-activated protein kinase $\alpha 2$ catalytic subunit controls whole-body insulin sensitivity
}

\author{
Benoit Viollet, ${ }^{1}$ Fabrizio Andreelli, ${ }^{1}$ Sebastian B. Jørgensen, ${ }^{2}$ Christophe Perrin, ${ }^{3}$ \\ Alain Geloen, ${ }^{4}$ Daisy Flamez, ${ }^{5}$ James Mu, ${ }^{6}$ Claudia Lenzner, ${ }^{1}$ Olivier Baud, ${ }^{1}$ \\ Myriam Bennoun, ${ }^{1}$ Emmanuel Gomas, ${ }^{1}$ Gaël Nicolas, ${ }^{1}$ Jørgen F.P. Wojtaszewski, ${ }^{2}$ \\ Axel Kahn, ${ }^{1}$ David Carling, ${ }^{7}$ Frans C. Schuit, ${ }^{5}$ Morris J. Birnbaum, ${ }^{6}$ Erik A. Richter, ${ }^{2}$ \\ Rémy Burcelin, ${ }^{3}$ and Sophie Vaulont ${ }^{1}$
}

${ }^{1}$ Department of Genetic, Development, and Molecular Pathology, Institut Cochin, Institut National de la Santé et de la
Recherche Médicale (INSERM), Centre National de la Recherche Scientifique (CNRS), René Descartes University, Paris, France
${ }^{2}$ Copenhagen Muscle Research Centre, Department of Human Physiology, Institute of Exercise and Sport Sciences,
University of Copenhagen, Copenhagen, Denmark
${ }^{3}$ Unité Mixte de Recherche 5018, CNRS, Paul Sabatier University, Rangueil Hospital, Toulouse, France
${ }^{4}$ INSERM, Institut National des Sciences Appliquées-Lyon, Villeurbanne, France
${ }^{5}$ Diabetes Research Center, Laboratory of Biochemistry, Vrije Universiteit Brussel, Brussels, Belgium
${ }^{6}$ Howard Hughes Medical Institute, University of Pennsylvania School of Medicine, Philadelphia, Pennsylvania, USA
${ }^{7}$ Cellular Stress Group, Medical Research Council Clinical Sciences Centre, Hammersmith Hospital, London, United Kingdom

AMP-activated protein kinase (AMPK) is viewed as a fuel sensor for glucose and lipid metabolism. To better understand the physiological role of AMPK, we generated a knockout mouse model in which the AMPK $\alpha 2$ catalytic subunit gene was inactivated. AMPK $\alpha 2^{-/-}$mice presented high glucose levels in the fed period and during an oral glucose challenge associated with low insulin plasma levels. However, in isolated $A M P K \alpha 2^{-/-}$pancreatic islets, glucose- and L-arginine-stimulated insulin secretion were not affected. $A M P K \alpha 2^{-/-}$mice have reduced insulin-stimulated whole-body glucose utilization and muscle glycogen synthesis rates assessed in vivo by the hyperinsulinemic euglycemic clamp technique. Surprisingly, both parameters were not altered in mice expressing a dominant-negative mutant of AMPK in skeletal muscle. Furthermore, glucose transport was normal in incubated isolated $A M P K \alpha 2^{-/-}$muscles. These data indicate that $\mathrm{AMPK} \alpha 2$ in tissues other than skeletal muscles regulates insulin action. Concordantly, we found an increased daily urinary catecholamine excretion in $A M P K \alpha 2^{-/-}$mice, suggesting altered function of the autonomic nervous system that could explain both the impaired insulin secretion and insulin sensitivity observed in vivo. Therefore, extramuscular AMPK $\alpha 2$ catalytic subunit is important for whole-body insulin action in vivo, probably through modulation of sympathetic nervous activity.

J. Clin. Invest. 111:91-98 (2003). doi:10.1172/JCI200316567.

\section{Introduction}

The AMP-activated protein kinase (AMPK) has been proposed to act as a fuel sensor capable of mediating the cellular adaptation to nutritional and environmental variations (1). AMPK is a ubiquitous serine/threonine protein kinase activated in response to environmental or nutritional stress factors that deplete intracellular ATP levels. AMPK is a heterotrimeric enzyme consisting of an

Received for publication August 1, 2002, and accepted in revised form November 12, 2002.

Address correspondence to: B. Viollet, Institut Cochin, Département GDPM, 24 Rue du Faubourg Saint-Jacques 75014 Paris, France. Phone: 33-1-44-41-2408; Fax: 33-1-44-41-2421; E-mail: viollet@cochin.inserm.fr.

Benoit Viollet and Fabrizio Andreelli contributed equally to this work.

Conflict of interest: The authors have declared that no conflict of interest exists.

Nonstandard abbreviations used: AMP-activated protein kinase (AMPK); 5-aminoimidazole-4-carboxamide-1- $\beta$-D-ribofuranoside (AICAR); kinase-dead AMPK $\alpha 2$ transgenic (Tg-KD-AMPK $\alpha 2$ ); oral glucose tolerance test (OGTT); acetyl-CoA carboxylase (ACC). $\alpha$ catalytic subunit and noncatalytic regulatory $\beta$ and $\gamma$ subunits. Two isoforms have been identified for both the $\alpha$ subunit ( $\alpha 1$ and $\alpha 2$ ) and $\beta$ subunit ( $\beta 1$ and $\beta 2$ ), and three isoforms have been reported for the $\gamma$ subunit $(\gamma 1$, $\gamma 2$, and $\gamma 3$ ). Regulation of AMPK activity is complex, involving allosteric activation by AMP and covalent modification by phosphorylation via an upstream AMPK kinase (2). Phosphorylation of threonine 172 in the $\alpha$ subunit of AMPK is essential for its activation (2).

Metabolic actions of AMPK have been extensively studied in skeletal muscle. Activation of AMPK by 5 -aminoimidazole-4-carboxamide-1- $\beta$-D-ribofuranoside (AICAR) has been demonstrated to increase muscle glucose uptake in vivo and in vitro via an acute insulin-independent mechanism $(3,4)$ and to decrease the glycogen synthase activity ratio (5). Implication of AMPK in the physiology of tissues other than skeletal muscle has also been suggested by findings in liver $(6-8)$, pancreas $(9,10)$, and adipose tissue $(4,7,11,12)$. Lastly, AMPK is also expressed in the CNS (13), but the role of AMPK in this tissue remains to be determined. 
In skeletal muscle, the actions of AMPK are thought to be mediated mainly through the AMPK $\alpha 2$ isoform $(5,14,15)$. In other tissues, the physiological role of this isoform in vivo is less clear. To get more insights into this issue, we knocked out the $A M P K \alpha 2$ gene. In the present study, we show that $A M P K \alpha 2^{-/-}$mice exhibit glucose intolerance that is associated with low plasma insulin levels and reduced muscle glycogen synthesis during hyperinsulinemic clamp conditions. Reduction of insulin sensitivity was not dependent on muscle AMPK activity, since mice expressing a dominant-negative mutant of AMPK in skeletal muscle are not insulin resistant. Finally, $A M P K \alpha 2^{-/-}$mice have increased catecholamine urinary excretion, suggesting increased sympathetic tone. Consequently, our data suggest that the $\alpha 2$ catalytic subunit of AMPK plays a major role in vivo as a fuel metabolic sensor by modulating the activity of the autonomous nervous system.

\section{Methods}

Gene targeting and generation of $A M P K \alpha 2$ gene knockout mice. $A M P K \alpha 2$ genomic clones were isolated after screening a mouse 129 strain genomic library (Stratagene, Loyola, California, USA). The targeting construct was generated by flanking exon $\mathrm{C}$, which encodes the AMPK $\alpha 2$ catalytic domain (corresponding to amino acids 189-260), with loxP sites for the Cre recombinase and inserting a PGK promoter-driven neomycin selection cassette flanked by an additional loxP site. The targeting construct was linearized and electroporated into $129 /$ Sv MPI-I embryonic stem cells. Targeted clones were identified by Southern blot analysis of HindIIIdigested DNA using a flanking $5^{\prime}$ DNA fragment as a hybridization probe and PCR analysis. Cells expanded from targeted clones were injected into C57BL6 blastocysts, and germline-transmitting chimeric animals were mated with $\mathrm{C} 57 \mathrm{BL} / 6$ mice. The resulting heterozygous offspring were bred with "deleter" EIIa-Cre transgenic mice, in which Cre is expressed in the germ cells, to produce $A M P K \alpha 2^{+/-}$mice (16). These mice were crossed to generate control and mutant mice. Southern blot analysis of HindIII-digested DNA with an internal probe (Figure 1a) and PCR analysis were used to genotype mice.

Animals. Control, $A M P K \alpha 2^{-/-}$, and kinase-dead AMPK $\alpha 2$ transgenic (Tg-KD-AMPK $\alpha 2)$ male mice were studied at 12 weeks of age. The establishment and characterization of Tg-KD-AMPK $\alpha 2$ mice were previously reported (17). Animals were housed under controlled temperature $\left(21^{\circ} \mathrm{C}\right)$ and lighting, with 12 hours of light (7:00 am to 7:00 pm) and 12 hours of dark (7:00 pm to 7:00 am), and had free access to water and a standard mouse chow diet. All procedures were performed in accordance with the principles and guidelines established by the European Convention for the Protection of Laboratory Animals.

Body weight, food intake, and body composition. Mice were weighed weekly after 3 weeks of age. Food intake was measured daily for a period of 3 days using metabolic cages (Marty Technologie, Paris, France) that allow free access to tap water and food. Body composition analysis was performed on anesthetized living mice by a dual-energy $x$-ray absorptiometry method using a small animal densitometer (PIXImus Lunar; GE Medical Systems, Madison, Wisconsin, USA). Careful dissection and weighing of individual organs was also performed. Tissue triglycerides were extracted with acetone, and triglyceride content was measured with a commercial kit (Sigma-Aldrich, St. Louis, Missouri, USA).

Blood and urinary parameters. Blood was withdrawn from the tail using EDTA-aprotinin as the anticoagulant. In the fed state, blood was collected at 9:00 pm. For fasting experiments, food was removed at 5:00 pm, and the mice were kept in a clean new cage for 5 hours before blood collection. During the oral glucose tolerance test (OGTT) and AICAR tolerance test, blood glucose levels were assessed using a glucometer (Glucotrend II; Roche Diagnostics, Meylan, France). Serum insulin concentrations were assessed using a rat insulin ELISA kit with a mouse insulin standard (Crystal Chem Inc., Chicago, Illinois, USA). Serum leptin concentrations were assessed with a mouse leptin ELISA kit (Crystal Chem Inc.). Serum concentrations of potassium, sodium, triglycerides, FFAs, glycerol, total and HDL cholesterol, creatinine, and urea were determined using an automated Monarch device (Instrumentation Laboratory Co., Lexington, Massachusetts, USA). For determination of urinary levels of catecholamines, animals were housed in individual metabolic cages, and daily urinary catecholamine excretion during 3 consecutive days was determined by reverse-phase HPLC (performed at Cochin Hospital, Paris, France).

Glucose and AICAR tolerance tests. During OGTT and AICAR tolerance testing, blood was collected from the tail vein at $0,20,40,60,80,100$, and 120 minutes for determination of glucose levels. OGTTs were performed in the morning after an overnight fast by oral administration of $3 \mathrm{~g}$ glucose per $\mathrm{kg}$ body weight. Blood was also collected at time 20 minutes in chilled heparinized tubes for determination of plasma insulin levels. To study the effect of $\alpha$-adrenergic antagonist on glucose tolerance, mice were injected intraperitoneally with $10 \mathrm{mg} / \mathrm{kg}$ phentolamine 30 minutes before glucose challenge. To study the effect of $\beta$-adrenergic antagonist on glucose tolerance, mice were injected intraperitoneally with $10 \mathrm{mg} / \mathrm{kg}$ propranolol $30 \mathrm{~min}$ utes before glucose challenge. AICAR tolerance tests were performed in the morning by intraperitoneal injection of $0.25 \mathrm{~g}$ AICAR per $\mathrm{kg}$ body weight into overnight-fasted mice (17).

Hyperinsulinemic englycemic clamp procedures. To determine the rate of glucose utilization, an indwelling catheter was inserted into the femoral vein under anesthesia, sealed under the back skin, and glued on top of the skull (18). The mice were then housed individually. After 2 days, they showed normal feeding behavior and motor activity. The mice were allowed to recover for 4-6 days. On the day of the experiment, the mice were fast- 


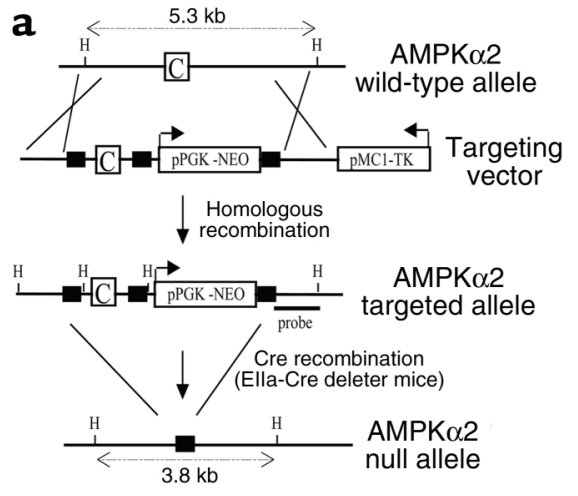

b
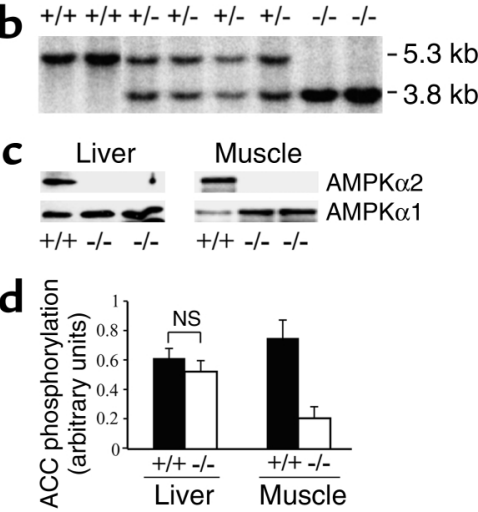

\section{Figure 1}

Generation of mice lacking AMPK $\alpha 2$. (a) Schematic representation (not to scale) of genomic structure of $A M P K \alpha 2$ wild-type allele, $A M P K \alpha 2$ gene-targeting construct, $A M P K \alpha 2$ targeted allele, and $A M P K \alpha 2$ null allele. Squares indicate loxP sites and H's indicate HindIII restriction sites. $C$ corresponds to the exon encoding the $A M P K \alpha 2$ catalytic domain (amino acids 189-260) (b) Southern blot analysis after HindIII digestion of tail DNA from offspring derived from heterozygous intercrosses. Expected fragment sizes of the AMPK 22 wild-type (+/+; $5.3 \mathrm{~kb})$ and null (-/-; $3.8 \mathrm{~kb}$ ) alleles after Hindlll digestion and hybridization with the indicated probe (solid bar in a) are shown. (c) Western blot analysis of AMPK $\alpha 1$ and AMPK $\alpha 2$ proteins in liver and gastrocnemius muscle from control $(+/+)$ and $A M P K \alpha 2^{-/-}$mice. (d) Phosphorylation level of ACC in liver and gastrocnemius muscle from control and $A M P K \alpha 2^{-1-}$ mice.

ed for 6 hours. The whole-body glucose utilization rate was determined under basal and hyperinsulinemic euglycemic conditions. In the basal state, HPLC-purified D- $\left(3-{ }^{3} \mathrm{H}\right)$-glucose (NEN Life Science Products Inc., Boston, Massachusetts, USA) was continuously infused through the femoral vein at a rate of $10 \mu \mathrm{Ci} / \mathrm{kg}$.min for 3 hours. In the hyperinsulinemic condition, insulin was infused at a rate of $6 \mathrm{mU} / \mathrm{kg}$.min for 3 hours; D- $\left(3-{ }^{3} \mathrm{H}\right)$ glucose was infused at rate of $30 \mu \mathrm{Ci} / \mathrm{kg}$.min - a higher rate than for the basal condition, to ensure a detectable plasma D- $\left(3-{ }^{3} \mathrm{H}\right)$-glucose enrichment. Throughout the infusion, blood glucose was assessed from blood samples and euglycemia was maintained by periodically adjusting a variable infusion of $16.5 \%(\mathrm{wt} / \mathrm{vol})$ glucose. Plasma glucose concentrations, D- $\left(3-{ }^{3} \mathrm{H}\right)$-glucose specific activity, and ${ }^{3} \mathrm{H}_{2} \mathrm{O}$ and $\mathrm{D}-\left(3-{ }^{3} \mathrm{H}\right)$-glucose enrichments were determined as previously described (18). Glucose turnover and whole-body glycolysis rate were calculated as described (18). Whole-body glycogen synthesis was calculated by subtracting the whole-body glycolytic rate from the glucose turnover rate. The mean was calculated for each timepoint for this period. The mean value of mice from the same group was reported. Mice showing variations in specific activity larger than $15 \%$ were excluded from the study.

Determination of total glycogen content and glycogen synthesis rate in skeletal muscle and liver. At completion of the infusion, the hind limb and the main lobe of the liver were removed and ground into liquid nitrogen for determination of total glycogen content and glycogen synthesis rate. Total glycogen was extracted from $20 \mathrm{mg}$ of liver or $100 \mathrm{mg}$ of muscle by digesting tissue samples in $\mathrm{KOH}$. An aliquot was neutralized with $\mathrm{HCl}$ and the glycogen content was assessed using amyloglucosidase (19). Muscle glycogen synthesis rate was determined by extracting glycogen with perchloric acid ( $6 \% \mathrm{wt} / \mathrm{vol})$ and precipitating glycogen with ethanol as described previously (20). The radioactive glycogen was counted and divided by the $\mathrm{D}-\left(3-{ }^{3} \mathrm{H}\right)$-glucose specific activity to determine the rate of synthesis.

Deoxyglucose uptake in isolated muscles. Mice were anesthetized with pentobarbital and soleus and extensor digitorum longus muscles were exposed. Ligatures were placed around the tendon at each end of the muscle. Muscles were suspended at resting tension (4-5 $\mathrm{m} \mathrm{New}-$ tons) and incubated at $30^{\circ} \mathrm{C}$ for 10 minutes at basal conditions in incubation chambers (Multi myograph system organ bath 700MO; Danish Myo Technology A/S, Aarhus, Denmark) oxygenated with $95 \% \mathrm{O}_{2}$ and $5 \% \mathrm{CO}_{2}$ gas. Basal medium consisted of $0.01 \% \mathrm{BSA}, 8 \mathrm{mM}$ mannitol, and $2 \mathrm{mM}$ pyruvate in Krebs-Henseleit buffer $(118.5 \mathrm{mM}$ $\mathrm{NaCl}, 24.7 \mathrm{mM} \mathrm{NaHCO} 3,4.74 \mathrm{mM} \mathrm{KCl}, 1.18 \mathrm{mM}$ $\mathrm{MgSO}_{3}, 1.18 \mathrm{KH}_{2} \mathrm{PO}_{4}$, and $2.5 \mathrm{CaCl}_{2}, \mathrm{pH}$ 7.4). After basal incubation the medium was aspirated and exchanged with medium containing $600 \mu \mathrm{U}$ insulin $/ \mathrm{ml}$ (100 IU/ml Actrapid; Novo Nordisk A/S, Bagsvær, Denmark) for 30 minutes. 2-deoxy-D-glucose uptake measurements were initiated by incubation in a medium containing $600 \mu \mathrm{U}$ insulin/ml, $1 \mathrm{mM} 2$ - $\left[2,6-{ }^{3} \mathrm{H}\right]$ deoxyD-glucose with a specific activity in the medium of $0.128 \mathrm{mCi} / \mathrm{ml}$, and $8 \mathrm{mM}\left[1-{ }^{14} \mathrm{C}\right]$ mannitol with a specific activity in the medium of $0.083 \mathrm{mCi} / \mathrm{ml}$ (Amersham Biosciences Europe, Freiburg, Germany). Uptake was measured for 10 minutes before the muscle was washed in ice-cold Krebs-Henseleit buffer and quickly frozen with aluminum tongs precooled in liquid nitrogen. Frozen muscles were digested in $250 \mu 11 \mathrm{M} \mathrm{NaOH}$ at $80^{\circ} \mathrm{C}$ for 10 minutes. The solution was neutralized with $250 \mu \mathrm{l} 1 \mathrm{M} \mathrm{NaCl}$ and spun at $13,000 \mathrm{~g}$ for $2 \mathrm{~min}$ utes. Radioactivity in the supernatant was measured using liquid scintillation (Tri-Carb 2000; Packard Instruments, Greve, Denmark).

Insulin release from isolated islets of Langerhans. The insulin-secretory response of $A M P K \alpha 2^{---} \beta$ cells was studied in collagenase-isolated islets of Langerhans. After isolation, islets were cultured for 16 hours in Ham's F10 medium containing $10 \mathrm{mM}$ glucose. Insulin release was measured by perifusion experiments in a multiple microchamber module (Endotronics Inc., Coon Rapids, Minnesota, USA) as previously described (21). Approximately 200 islets were loaded onto Biogel P2 (Biorads Labs, Richmond, California, USA) in a col- 
Table1

Body composition, food intake, and triglyceride content of liver, gastrocnemius muscle, and pancreas of $A M P K \alpha 2^{-/-}$mice

\begin{tabular}{|c|c|c|}
\hline & Control & $A M P K \alpha 2^{-/}$ \\
\hline Body weight (g) & $28.8 \pm 0.9$ & $29.6 \pm 0.8$ \\
\hline Fat-free mass $(\mathrm{g})^{\mathrm{A}}$ & $21.6 \pm 0.6$ & $21.7 \pm 0.6$ \\
\hline$\%$ fat mass ${ }^{A}$ & $7.1 \pm 0.3$ & $6.7 \pm 0.2$ \\
\hline Food intake $(\mathrm{g} / \mathrm{d})$ & $3.7 \pm 0.1$ & $3.8 \pm 0.1$ \\
\hline Liver TG content (mg/g tissue) & $11.2 \pm 0.7$ & $14.0 \pm 3.2$ \\
\hline Muscle TG content (mg/g tissue) & $11.7 \pm 2.7$ & $8.1 \pm 0.9$ \\
\hline Pancreas TG content (mg/g tissue) & $6.1 \pm 1.2$ & $5.2 \pm 0.6$ \\
\hline
\end{tabular}

ABody composition was assessed by biphotonic absorptiometry. All data are expressed as mean \pm SEM ( $n=6-10$ mice/group). $P$ not significant between groups by unpaired, two-tailed Student $t$ test. TG, triglyceride.

umn and preperifused for 20 minutes in Ham's F10 medium supplemented with $0.5 \%$ (wt/vol) BSA, $2 \mathrm{mM}$ glutamine, $2 \mathrm{mM} \mathrm{CaCl}_{2}$, and $3 \mathrm{mM}$ glucose, equilibrated with $95 \% \mathrm{O}_{2}$ and $5 \% \mathrm{CO}_{2}$. At a flow rate of 0.5 $\mathrm{ml} / \mathrm{min}, 15$-minute pulses of $3 \mathrm{mM}$ glucose were alternated with 10 -minute pulses of $7.5 \mathrm{mM}$ glucose, $10 \mathrm{mM}$ glucose, $20 \mathrm{mM}$ glucose, and $10 \mathrm{mM}$ glucose with 20 $\mathrm{mM}$ L-arginine (Sigma-Aldrich). Samples were collected every minute and assayed for immunoreactive insulin with guinea pig anti-insulin serum (Linco Research Inc., St. Charles, Missouri, USA). Results were expressed as percentages of the insulin content measured in each individual batch of islets after finishing the experiment by sonicating the Biogel P2 containing the islets in $5 \mathrm{ml}$ of $2 \mathrm{mM}$ acetic acid and $0.25 \%$ (wt/vol) BSA.

Western blot analysis. Liver AMPK was obtained by polyethylene glycol precipitation (2), and muscle AMPK was prepared as previously described (5). AMPK catalytic subunits were detected using specific antiAMPK $\alpha 1$ and anti-AMPK $\alpha 2$ antibodies (kindly provided by G. Hardie, Dundee University, Dundee, Scotland, United Kingdom). The phosphorylation status of acetyl-CoA carboxylase (ACC) was visualized using an anti-phospho-ACC (serine 79) antibody (Upstate Biotechnology Inc., Lake Placid, New York, USA).

Statistical analysis. Data are expressed as mean \pm SEM. Statistical analyses were carried out using an unpaired, two-tailed Student $t$ test, and the null hypothesis was rejected at 0.05 .

\section{Results}

Animal model: $A M P K \alpha 2^{-/-}$mice. $A M P K \alpha 2$ gene knockout was obtained using a targeting vector inserting loxP sites flanking the sequence containing the enzymatic catalytic site (Figure 1a). Deletion of the targeted allele was carried out by mating to EIIa-Cre transgenic mice to cause germline excision (16). Mice harboring the deleted allele were identified by

\section{Table 2}

Southern blot analysis (Figure 1b). Using RT-PCR analysis, no amplification of the region corresponding to the catalytic domain of AMPK $\alpha 2$ was observed in the liver, skeletal muscle, or pancreas of $A M P K \alpha 2^{-/-}$ mice (data not shown). Western blot analysis of protein extracts prepared from $A M P K \alpha 2^{-/-}$liver and skeletal muscle showed undetectable AMPK $\alpha 2$ protein (Figure 1c). The AMPK $\alpha 1$ protein level was similar in the liver of $A M P K \alpha 2^{-/-}$and control mice (Figure 1c). In contrast, in $A M P K \alpha 2^{-/-}$mice, AMPK $\alpha 1$ protein was increased 1.8-fold in gastrocnemius muscle (Figure 1c). Phosphorylation of ACC was decreased in gastrocnemius muscle 3.5-fold, while it was unchanged in the liver compared with controls (Figure 1d).

Physical appearance, body weight, body composition, and triglyceride content in tissues of $A M P K \alpha 2^{-1-}$ mice. $A M P K \alpha 2^{-/-}$mice from heterozygous mating were born with the expected mendelian ratio. $A M P K \alpha 2^{-/-}$mice are fertile, appear indistinguishable from their wildtype littermates, and have a normal life span. No significant difference in body weight or food intake was observed between the two groups (Table 1). Body composition was similar for both groups as assessed both by biphotonic absorptiometry (Table 1) and careful dissection and weighing of individual organs (data not shown). Triglyceride content in liver, gastrocnemius muscle, and pancreas was similar in $A M P K \alpha 2^{-/-}$mice and controls (Table 1).

Metabolic parameters. In fasted conditions, plasma glucose and insulin levels were similar in $A M P K \alpha 2^{-/-}$ mice and controls, while plasma FFA concentrations were increased in $A M P K \alpha 2^{-/-}$mice (Table 2). Glycerol plasma levels have a tendency to be higher in $A M P K \alpha 2^{-/-}$mice but do not reach statistical significance (Table 2). In the fed state, $A M P K \alpha 2^{-/-}$mice were characterized by higher plasma glucose and plasma FFA concentrations than were found in control mice, while plasma insulin and leptin levels were lower (Table 2). No difference between plasma levels of total and HDL cholesterol, sodium, potassium, creatinine, or urea were noted between $A M P K \alpha 2^{-/-}$and control mice (Table 2 and data not shown).

Metabolic parameters of $A M P K \alpha 2^{-/-}$mice in fasted and fed periods

\begin{tabular}{lcccc} 
& \multicolumn{2}{c}{ Fasted } & \multicolumn{2}{c}{ Fed } \\
& Control & AMPK $\alpha 2^{-/-}$ & Control & AMPK $\alpha 2^{-/-}$ \\
Glycemia $(\mathrm{mg} / \mathrm{dl})$ & $102 \pm 5$ & $101 \pm 13$ & $141 \pm 10$ & $171 \pm 9^{\mathrm{B}}$ \\
Insulin $(\mathrm{ng} / \mathrm{ml})$ & $0.46 \pm 0.17$ & $0.29 \pm 0.08$ & $1.35 \pm 0.07$ & $1.07 \pm 0.12^{\mathrm{B}}$ \\
Leptin $(\mathrm{ng} / \mathrm{ml})$ & $0.38 \pm 0.10$ & $0.38 \pm 0.13$ & $4.31 \pm 0.24$ & $2.65 \pm 0.49^{\mathrm{A}}$ \\
FFA $(\mathrm{mM})$ & $1.10 \pm 0.04$ & $1.37 \pm 0.06^{\mathrm{A}}$ & $0.73 \pm 0.06$ & $0.95 \pm 0.07^{\mathrm{B}}$ \\
Glycerol $(\mu \mathrm{M})$ & $367 \pm 14$ & $388 \pm 15$ & $281 \pm 24$ & $312 \pm 31$ \\
TG $(\mathrm{mM})$ & $0.58 \pm 0.02$ & $0.74 \pm 0.07$ & $0.72 \pm 0.05$ & $0.91 \pm 0.13$ \\
$\beta$-hydroxybutyrate $(\mathrm{mM})$ & $0.98 \pm 0.09$ & $1.17 \pm 0.11$ & $0.07 \pm 0.01$ & $0.08 \pm 0.01$ \\
Total cholesterol $(\mathrm{mM})$ & $2.3 \pm 0.2$ & $2.9 \pm 0.1$ & $2.3 \pm 0.2$ & $2.6 \pm 0.3$ \\
HDL cholesterol $(\mathrm{mM})$ & $1.7 \pm 0.1$ & $1.9 \pm 0.2$ & $1.5 \pm 0.3$ & $1.7 \pm 0.2$ \\
& & & & \\
\hline
\end{tabular}

All data are expressed as mean $\pm \operatorname{SEM}\left(n=6-10\right.$ mice/group). ${ }^{A} P<0.01,{ }^{B} P<0.05$ vs. control group by unpaired, two-tailed Student $t$ test. 

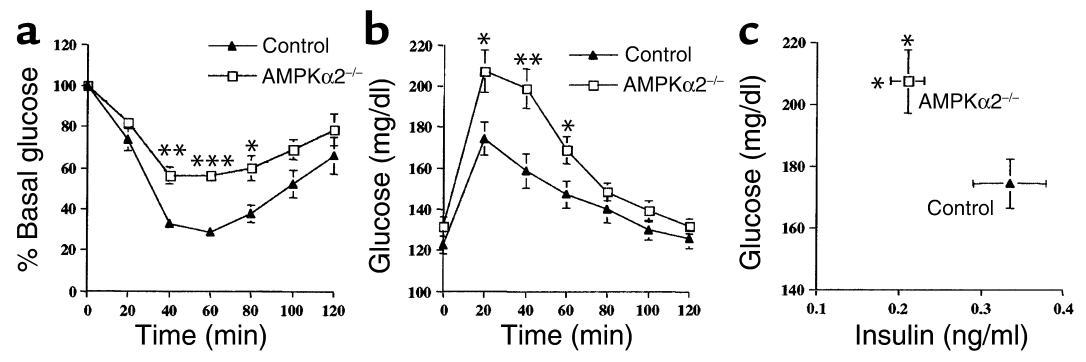

Figure 2

AMPK $\alpha 2^{-/-}$mice are AICAR-resistant, glucose intolerant, and exhibit impaired glucose-stimulated insulin secretion. (a) AICAR tolerance test. (b) OGTT. (c) Plasma glucose and insulin levels at time 20 minutes during OGTT. All results are expressed as mean $\pm \operatorname{SEM}(n=6-10)$. ${ }^{*} P<0.05,{ }^{*} P<0.001,{ }^{*}{ }^{*} P<0.0001$ vs. control group by unpaired, two-tailed Student $t$ test. NS, not significant.

AMPK $\alpha 2^{-/-}$mice are AICAR-resistant, glucose intolerant, and have reduced glucose-stimulated insulin secretion. To investigate in vivo to what extent remaining AMPK $\alpha 1$ protein levels can substitute for AMPK $\alpha 2$, we performed an AICAR tolerance test. The relative insensitivity to hypoglycemia-mediated AICAR effects observed in $A M P K \alpha 2^{-/-}$mice (Figure 2a) suggests that AMPK $\alpha 1$ cannot fully compensate for the lack of $A M P K \alpha 2$ in $A M P K \alpha 2^{--}$mice. To investigate the dynamic response of $A M P K \alpha 2^{-/-}$mice to increased glucose concentrations, an oral glucose challenge was performed. Following glucose absorption, AMPK $\alpha 2^{-1-}$ mice have a markedly increased blood glucose excursion, demonstrating glucose intolerance (Figure $2 \mathrm{~b}$ ). Insulinemia determined at time 20 minutes was significantly lower in $A M P K \alpha 2^{-/-}$mice (Figure 2c).

Glucose-and L-arginine-stimulated insulin secretion are normal in isolated pancreatic islets of AMPKO2 $2^{-/-}$mice. No significant difference in insulin release was observed between control and $A M P K \alpha 2^{-/-}$pancreatic islets for basal ( $3 \mathrm{mM}$ glucose) and stimulatory glucose concentrations $(7.5 \mathrm{mM}, 10 \mathrm{mM}$, and $20 \mathrm{mM}$ glucose) or when challenged with $20 \mathrm{mM}$ L-arginine (Figure 3). Furthermore, the insulin content of $A M P K \alpha 2^{-/-}$and control islets was similar $(67.2 \pm 16.2$ vs. $63.9 \pm 16.5 \mathrm{ng} /$ islet in controls; $P$ not significant).

$A M P K \alpha 2^{-1-}$ mice are insulin resistant while $\mathrm{Tg}-K D$ $A M P K \alpha 2$ mice are not. In the basal condition, endogenous glucose production, glycolysis rate, and wholebody glycogen synthesis rate were similar between $A M P K \alpha 2^{-/-}$and control mice (Table 3). In vivo muscle glycogen synthesis rate and total glycogen content were similar in both groups (Table 3). During hyperinsulinemic

\section{Figure 3}

Glucose- and L-arginine-stimulated (L-Arg) insulin secretion in isolated $A M P K \alpha 2^{-/-}$islets. All results are expressed as mean $\pm \operatorname{SEM}(n=4)$. $P$ not significant between groups by unpaired, two-tailed Student $t$ test. euglycemic clamp, plasma glucose and insulinemia were comparable in $A M P K \alpha 2^{-/-}$and control mice (plasma glucose: $109.8 \pm 7.2 \mathrm{mg} / \mathrm{dl}$ in $A M P K \alpha 2^{-/-}$mice vs. $97.2 \pm 3.6$ $\mathrm{mg} / \mathrm{dl}$ in controls, $P$ not significant; plasma insulin: $159.7 \pm 22.6 \mathrm{mU} / \mathrm{l}$ in $A M P K \alpha 2^{-/-}$mice vs. $146.9 \pm 22.5$ $\mathrm{mU} / \mathrm{l}$ in controls, $P$ not significant). Insulin-stimulated whole-body glucose turnover rate was decreased in $A M P K \alpha 2^{-/-}$mice compared with controls (Table 3). Insulin-stimulated whole-body glycolysis was similar in both groups, while the insulin-stimulated whole-body glycogen synthesis rate was dramatically decreased in $A M P K \alpha 2^{-/-}$mice (Table 3). Muscle glycogen synthesis rate and total muscle glycogen content were severely reduced in $A M P K \alpha 2^{-/-}$mice compared with controls at the end of the clamp (Table 3). Because glucose uptake is largely rate limiting for glycogen synthesis in muscle during clamp study, we assayed uptake of deoxyglucose into isolated muscle in the presence of insulin. Basal and insulin-stimulated glucose uptake were similar in isolated extensor digitorum longus and soleus muscles from controls and $A M P K \alpha 2^{-/-}$mice (Figure 4, a and b). In addition, total glycogen content in skeletal muscle of random-fed animals was similar between $A M P K \alpha 2^{---}$and control mice $(0.312 \pm 0.106$ vs. $0.358 \pm 0.072 \mu \mathrm{g} / \mathrm{mg}$ in controls, respectively, $P$ not significant). Lastly, endogenous hepatic glucose production was totally inhibited in both groups, suggesting no hepatic insulin resistance (data not shown). Furthermore, no defect was detected in glycogen synthesis or total glycogen content in the liver of $A M P K \alpha 2^{-/-}$and control mice in either basal or clamp studies (data not shown).

To further investigate the role of muscle AMPK in the development of insulin resistance, we performed hyperinsulinemic euglycemic clamps in transgenic mice expressing a kinase-dead mutant of AMPK in skeletal muscle (Tg-KD-AMPK $\alpha 2$ mice) and their respective nontransgenic controls (17). Oral glucose tolerance was comparable between the two groups (data not shown). During the clamp, plasma glucose

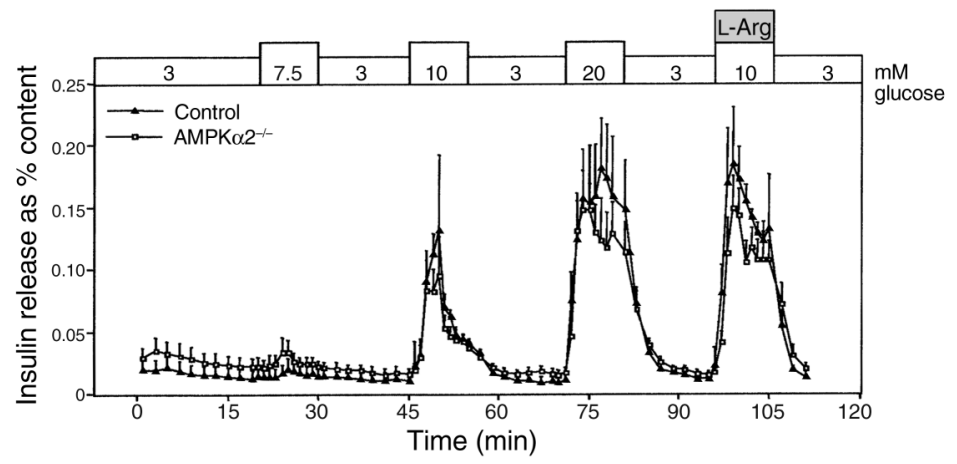


Table 3

Metabolic parameters of $A M P K \alpha 2^{-/-}$and $\mathrm{Tg}-\mathrm{KD}-\mathrm{AMPK} \alpha 2$ mice during basal and hyperinsulinemic euglycemic clamp studies

$\begin{array}{cccccc}\text { Weight } & \begin{array}{c}\text { Whole-body } \\ \text { glucose turnover }\end{array} & \begin{array}{c}\text { Whole-body } \\ \text { glycolysis rate }\end{array} & \begin{array}{c}\text { Whole-body glycogen } \\ \text { synthesis rate }\end{array} & \begin{array}{c}\text { Muscle glycogen } \\ \text { synthesis rate }\end{array} & \begin{array}{c}\text { Muscle glycogen } \\ \text { content }\end{array} \\ (\mathrm{g}) & (\mathrm{mg} / \mathrm{kg} / \mathrm{min}) & (\mathrm{mg} / \mathrm{kg} / \mathrm{min}) & (\mathrm{mg} / \mathrm{kg} / \mathrm{min}) & (\mathrm{ng} / \mathrm{mg} / \mathrm{min}) & (\mu \mathrm{g} / \mathrm{mg})\end{array}$

Basal

\begin{tabular}{|c|c|c|c|c|c|c|}
\hline $\begin{array}{l}\text { Control } \\
\text { AMPK } \alpha 2^{-/-}\end{array}$ & $\begin{array}{l}24.7 \pm 1.2 \\
24.7 \pm 1.0\end{array}$ & $\begin{array}{l}24.2 \pm 1.6 \\
25.6 \pm 1.9\end{array}$ & $\begin{array}{r}10.3 \pm 0.5 \\
9.2 \pm 0.7\end{array}$ & $\begin{array}{l}13.9 \pm 1.5 \\
16.4 \pm 2.0\end{array}$ & $\begin{array}{l}48.4 \pm 14.6 \\
15.7 \pm 4.1\end{array}$ & $\begin{array}{l}0.035 \pm 0.013 \\
0.020 \pm 0.006\end{array}$ \\
\hline \multicolumn{7}{|l|}{ Clamp } \\
\hline Control & $22.3 \pm 0.5$ & $90.6 \pm 4.3$ & $19.7 \pm 2.9$ & $71.0 \pm 2.5$ & $611.8 \pm 143.2$ & $0.458 \pm 0.113$ \\
\hline$A M P K \alpha 2^{-/-}$ & $21.4 \pm 0.5$ & $68.7 \pm 2.9^{\mathrm{A}}$ & $21.8 \pm 1.6$ & $46.9 \pm 2.9^{\mathrm{A}}$ & $143.9 \pm 17.0^{A}$ & $0.137 \pm 0.030^{B}$ \\
\hline NTg & $27.2 \pm 0.5$ & $64.2 \pm 7.0$ & $14.8 \pm 1.0$ & $45.9 \pm 6.9$ & $108.9 \pm 50.9$ & $0.175 \pm 0.053$ \\
\hline Tg-KD-AMPK $\alpha 2$ & $25.1 \pm 1.3$ & $72.9 \pm 5.3$ & $16.5 \pm 3.6$ & $56.4 \pm 7.3$ & $89.9 \pm 21.0$ & $0.172 \pm 0.050$ \\
\hline
\end{tabular}

All data are expressed as mean $\pm \operatorname{SEM}\left(n=6-12\right.$ mice/group). ${ }^{A} P<0.01,{ }^{B} P<0.05$ vs. control group by unpaired, two-tailed Student $t$ test. NTg, nontransgenic.

and insulinemia were comparable in Tg-KD-AMPK $\alpha 2$ and nontransgenic mice (plasma glucose: $93.6 \pm 1.8$ $\mathrm{mg} / \mathrm{dl}$ in Tg-KD-AMPK $\alpha 2$ mice vs. $95.4 \pm 9.0 \mathrm{mg} / \mathrm{dl}$ in nontransgenic controls, $P$ not significant; plasma insulin: $113.7 \pm 24.8 \mathrm{mU} / \mathrm{l}$ in Tg-KD-AMPK $\alpha 2$ mice vs. $145.7 \pm 22.9 \mathrm{mU} / \mathrm{l}$ in nontransgenic controls, $P$ not significant). Insulin-stimulated whole-body glucose turnover, whole-body glycogen synthesis rate, muscle glycogen synthesis rate, and total muscle glycogen content were similar in both groups (Table 3).

Increased daily urinary catecholamine excretion in AMPK $\alpha 2^{-/-}$mice. Daily epinephrine, norepinephrine, and dopamine excretion were significantly higher in $A M P K \alpha 2^{-/-}$mice than in controls (Figure 5, a-c). The response to a glucose challenge was dramatically improved in $A M P K \alpha 2^{-/-}$mice after treatment with $\alpha$-adrenergic blockers, while no change was observed in control mice (Figure 5, $\mathrm{d}$ and e). In contrast, $\beta$-adrenergic blockers did not modify glucose tolerance of $A M P K \alpha 2^{-/-}$mice (Figure 5, $\mathrm{d}$ and e).

\section{Discussion}

The primary goal of this study was to assess the role of the AMPK $\alpha 2$ isoform in controlling glucose metabolism in vivo. $A M P K \alpha 2^{-/-}$mice appear indistinguishable from their control littermates. Importantly, there is no difference in body composition, adiposity, or food intake between mutant and control mice. The most striking observation is reduced glucose tolerance in $A M P K \alpha 2^{-/-}$mice. We showed that this defect is linked with both reduced insulin release and decreased insulin sensitivity of peripheral tissues. Few data are available concerning regulation of insulin release by AMPK. Activation of AMPK has been shown to inhibit insulin secretion in vitro $(9,10)$. Here, we showed that while glucose-induced insulin secretion is clearly impaired in $A M P K \alpha 2^{-/-}$mice in vivo, basal and glucose- and L-arginine-stimulated insulin secretion in isolated pancreatic islets are similar in $A M P K \alpha 2^{-/-}$mice and controls. Furthermore, insulin content of islets and insulin gene transcription (data not shown) were not affected by $A M P K \alpha 2$ gene deletion. Taken together, these data indicate that the lack of insulin secretion observed in vivo in $A M P K \alpha 2^{-/-}$mice is not due to a primary defect in $\beta$ cell function. Hypokalemia or hyperleptinemia (22), known to modulate insulin secretion negatively in vivo, are not observed in $A M P K \alpha 2^{-/-}$mice. In addition, lipid content in pancreas was similar in $A M P K \alpha 2^{-/-}$ mice and controls, excluding a deleterious effect on insulin release by chronic accumulation of lipids (23, 24). An important regulator of insulin secretion is the fine-tuning of the balance between sympathetic and parasympathetic activity. This is critical for the $\beta$ cells, since epinephrine and norepinephrine directly and potently suppress $\beta$ cell function (25). $A M P K \alpha 2^{-/-}$mice exhibited higher catecholamine urinary excretion than did controls. Since catecholamines are known to inhibit insulin release, dysregulation in sympathetic tone observed in $A M P K \alpha 2^{-/-}$mice could be implicated in the reduction of insulin secretion. More importantly, no defect in glucose and insulin plasma levels was observed in mutant mice in the fasted state, suggesting that dysregulation of sympathetic tone is predominant in the fed period.

Glucose intolerance is due to both impaired insulin secretion and reduced insulin-stimulated glucose utilization. Therefore, we examined insulin sensitivity in peripheral tissues of $A M P K \alpha 2^{-/-}$mice using hyperinsu-
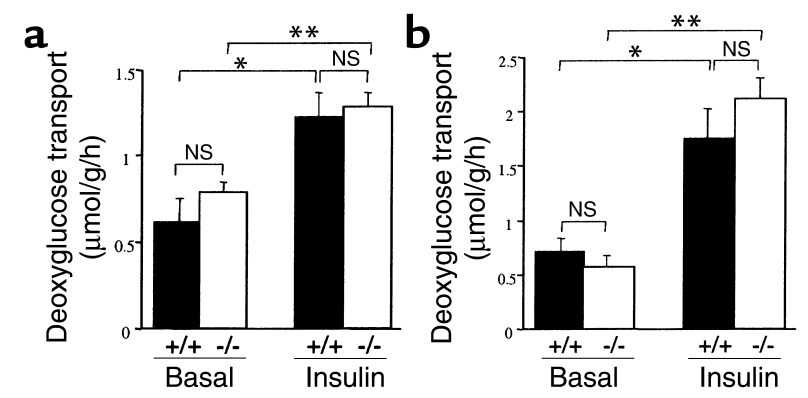

Figure 4

Insulin-stimulated glucose transport in isolated muscles from $A M P K \alpha 2^{-/-}$mice. Basal and insulin-stimulated glucose transport in (a) soleus and (b) extensor digitorum longus muscles from control and $A M P K \alpha 2^{-/-}$mice. All results are expressed as mean $\pm \operatorname{SEM}(n=4-7)$. ${ }^{*} P<0.05,{ }^{*} P<0.01$ vs. basal conditions by unpaired, two-tailed Student $t$ test; $P$ not significant (NS) vs. control group. 
linemic euglycemic clamp studies. To our surprise, $A M P K \alpha 2^{-/-}$mice displayed decreased whole-body insulin sensitivity, with a dramatic reduction in insulin-stimulated glycogen synthesis in skeletal muscle, while hepatic insulin sensitivity was preserved. Does $\alpha 2$ deletion in skeletal muscle directly alter insulin sensitivity? This does not seem to be the case since insulin sensitivity is unaltered in Tg-KDAMPK $\alpha 2$ mice, which express a dominant-negative mutant of AMPK in skeletal muscle (17). This points out that lack of AMPK activity in skeletal muscle is unable by itself to alter insulin sensitivity or glycogen synthesis in this tissue. Likewise, comparable muscle glycogen contents of $A M P K \alpha 2^{--}$and control mice during the random-fed period suggest that the balance between degradation and repletion of glycogen in muscle is intact in this model. In consequence, a defect in muscular glycogen synthesis was specifically observed in $A M P K \alpha 2^{-/-}$mice when insulinemia reached supraphysiological levels. Glucose uptake is largely rate limiting for glycogen synthesis in muscle during clamp study. As insulin induced a similar increase in deoxyglucose uptake in incubated extensor digitorum longus and soleus muscles, it is unlikely that primary defective glucose transport in muscle contributes to $A M P K \alpha 2^{---}$insulin resistance.

Another known important mechanism of insulin resistance in skeletal muscle is increased lipid availability or increased tissue uptake of FFA (26). AMPK regulates lipid oxidation in muscle by reducing ACC activity, which in turn decreases malonyl coenzyme A levels and increases mitochondrial uptake of FFAs. In $A M P K \alpha 2^{-/-}$ gastrocnemius muscle, we showed that $\alpha 1$ protein was increased by 1.8-fold (Figure 1c) but ACC phosphorylation was reduced by 3.5 -fold (Figure $1 \mathrm{~d}$ ). These data suggest that in skeletal muscle, the increased $\alpha 1$ protein levels in $A M P K \alpha 2^{-1-}$ mice is not sufficient to ensure normal phosphorylation of ACC. However, the 24-hour respiratory quotient, monitored by indirect calorimetry, was similar in $A M P K \alpha 2^{-/-}$and control mice (data not shown), suggesting that whole-body lipid oxidation is not altered by the lack of the AMPK $\alpha 2$ subunit. Furthermore, comparable skeletal muscle lipid content in both groups argues against any alteration of lipid oxidation rate in $A M P K \alpha 2^{--}$mice. Finally, we know that adipose tissue operates as an endocrine organ that releases a large number of hormones in response to specific extracellular stimuli or changes in metabolic status. Alteration of secretion of these proteins (which include TNF- $\alpha$, leptin, adipsin, resistin, and adiponectin) as a possible mechanism of $A M P K \alpha 2^{-/-}$mouse insulin resistance needs further investigation.

So how can we explain insulin resistance in $A M P K \alpha 2^{--}$ mice? The observation that $A M P K \alpha 2^{-\gamma^{-}}$mice exhibit altered glucose metabolism in vivo but not in isolated organs suggests that the defect is of central origin. It is known that integration of peripheral and central metabolic signals in the CNS during different metabolic situations such as fasting, fed state, and hyperinsulinemic clamp activates the autonomous nervous system, which in turn regulates glucose metabolism in peripheral tissues (27-30). As AMPK $\alpha 2$ is widely expressed in the brain (13), we hypothesized that lack of AMPK $\alpha 2$ in neurons could contribute to the metabolic defects observed in $A M P K \alpha 2^{-/-}$mice. Supporting this hypothesis, $A M P K O 2^{-/-}$mice exhibited a significant increase in daily urinary catecholamine excretion, suggesting higher sympathetic activation in these mice. Furthermore, the glucose intolerance of $A M P K \alpha 2^{-/-}$mice was dramatically improved after intraperitoneal injection of phentolamine (an $\alpha$-adrenergic receptor antagonist), while no change was observed after treatment of $A M P K \alpha 2^{-/-}$mice by propranolol (a $\beta$-adrenergic receptor antagonist). This suggested that the $\alpha$-adrenergic but not the $\beta$-adrenergic pathway is involved in the glucose intolerance observed in $A M P K \alpha 2^{---}$mice. It is well known that epinephrine overproduction inhibits insulin secretion, reduces insulin-stimulated glucose uptake in skeletal muscles, and alters muscle glycogen synthesis (31-35); all of these defects are present in $A M P K O 2^{-1-}$ mice in vivo. Moreover, normality of some metabolic parameters (fasting glucose and insulin plasma levels or skeletal muscle glycogen content in random-fed animals) suggests that exaggerated sympathetic tone in $A M P K \alpha 2^{-/-}$ mice is not permanent but is restricted to particular nutritional situations such as glucose challenge and hyperinsulinemic euglycemic clamps.
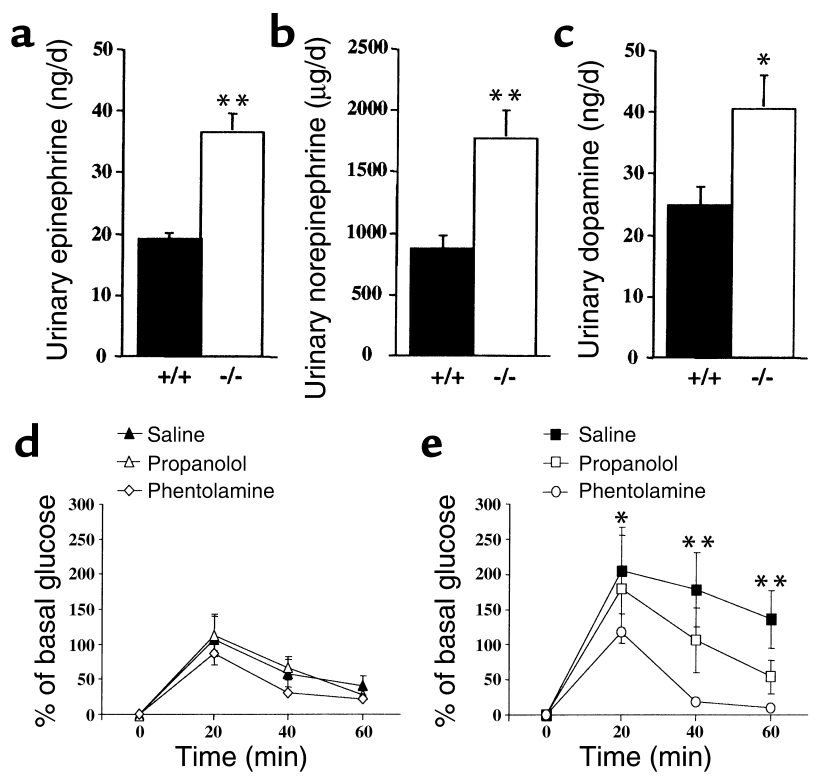

Figure 5

Increased daily urinary catecholamine excretion in $A M P K \alpha 2^{-/-}$mice. Daily urinary (a) epinephrine, (b) norepinephrine, and (c) dopamine excretion in $A M P K \alpha 2^{-/-}$mice. All results are expressed as mean \pm $\operatorname{SEM}(n=6) .{ }^{*} P<0.05,{ }^{*} P<0.01$ vs. control group by unpaired, two-tailed $t$ test. Also shown are effect of phentolamine and propranolol, $\alpha$ - and $\beta$-adrenergic blockers, respectively, on the response of glucose challenge of control (d) and $A M P K \alpha 2^{-1-}(\mathbf{e})$ mice. All results are expressed as mean $\pm \operatorname{SEM}(n=5) .{ }^{*} P<0.05,{ }^{*} P<0.01$, saline- vs. phentolamine-treated group by unpaired, two-tailed Student $t$ test; $P$ not significant for saline- vs. propranolol-treated group. 
The data presented here identify AMPK $\alpha 2$ as a major component in the control of insulin sensitivity and insulin secretion in vivo. We clearly demonstrated that the metabolic function of $A M P K \alpha 2^{---}$isolated skeletal muscle and pancreatic islets is normal, suggesting that the origin of the defects observed in vivo is located outside these tissues. In addition, we showed significant increased catecholamine excretion in $A M P K \alpha 2^{-/-}$mice. Thus, we hypothesize that lack of AMPK $\alpha 2$ in neurons reduces the ability to integrate peripheral metabolic signals into the brain and consequently alters the control of peripheral insulin sensitivity and insulin secretion by increasing sympathetic nervous activity.

\section{Acknowledgments}

We are grateful to A.K. Voss for the kind gift of embryonic stem cells. We thank D. Desmoulins (Cochin Hospital, Paris) for catecholamine measurement; $\mathrm{M}$. Muffat-Joly and J. Bauchet (Centre d'Explorations Fonctionnelles Intégré, Faculté de Médecine Xavier Bichat, Paris) for metabolic cage studies and determination of blood parameters; and C. Silve (Bichat Hospital) and GE Medical Systems for access to dual-energy $x$-ray absorptiometry. We appreciate assistance from D. Beaumont, T. Busnel, C. Postic, and A. Wood. This work was supported by INSERM, CNRS, the French Ministry for Research, the Danish National Research Foundation (grant 504-12), and the European Commission (grant QLG1-CT-2001-01488). F. Andreelli and S.B. Jørgensen were supported by postdoctoral fellowships from the European Commission, J.F.P. Wojtaszewski was supported by a postdoctoral fellowship from the Danish Medical Research Council, and G. Nicolas was supported by a postdoctoral fellowship from Aventis Laboratories.

1. Hardie, D.G., and Hawley, S.A. 2001. AMP-activated protein kinase: the energy charge hypothesis revisited. Bioessays. 23:1112-1119.

2. Hawley, S.A., et al. 1996. Characterization of the AMP-activated protein kinase kinase from rat liver and identification of threonine 172 as the major site at which it phosphorylates AMP-activated protein kinase. J. Biol. Chem. 271:27879-27887.

3. Hayashi, T., Hirshman, M.F., Kurth, E.J., Winder, W.W., and Goodyear, L.J. 1998. Evidence for 5' AMP-activated protein kinase mediation of the effect of muscle contraction on glucose transport. Diabetes. 47:1369-1373.

4. Bergeron, R., et al. 1999. Effect of AMPK activation on muscle glucose metabolism in conscious rats. Am. J. Physiol. 276:E938-E944.

5. Wojtaszewski, J.F., Jorgensen, S.B., Hellsten, Y., Hardie, D.G., and Richter, E.A. 2002. Glycogen-dependent effects of 5-aminoimidazole-4-carboxamide (AICA)-riboside on AMP-activated protein kinase and glycogen synthase activities in rat skeletal muscle. Diabetes. 51:284-292.

6. Vincent, M.F., Marangos, P.J., Gruber, H.E., and Van den Berghe, G. 1991. Inhibition by AICA riboside of gluconeogenesis in isolated rat hepatocytes. Diabetes. 40:1259-1266.

7. Bergeron, R., et al. 2001. Effect of 5-aminoimidazole-4-carboxamide-1beta-D-ribofuranoside infusion on in vivo glucose and lipid metabolism in lean and obese Zucker rats. Diabetes. 50:1076-1082.

8. Zhou, G., et al. 2001. Role of AMP-activated protein kinase in mechanism of metformin action. J. Clin. Invest. 108:1167-1174. doi:10.1172/JCI200113505.

9. Salt, I.P., Johnson, G., Ashcroft, S.J., and Hardie, D.G. 1998. AMP-activated protein kinase is activated by low glucose in cell lines derived from pancreatic beta cells, and may regulate insulin release. Biochem. J. 335:533-539.

10. Kowluru, A., Chen, H.Q., Modrick, L.M., and Stefanelli, C. 2001. Activation of acetyl-CoA carboxylase by a glutamate- and magnesium-sensitive protein phosphatase in the islet beta-cell. Diabetes. 50:1580-1587.

11. Sullivan, J.E., et al. 1994. Inhibition of lipolysis and lipogenesis in isolated rat adipocytes with AICAR, a cell-permeable activator of AMP-activated protein kinase. FEBS Lett. 353:33-36.

12. Corton, J.M., Gillespie, J.G., Hawley, S.A., and Hardie, D.G. 1995. 5-aminoimidazole-4-carboxamide ribonucleoside. A specific method for activating AMP-activated protein kinase in intact cells? Eur. J. Biochem. 229:558-565.

13. Turnley, A.M., et al. 1999. Cellular distribution and developmental expression of AMP-activated protein kinase isoforms in mouse central nervous system. J. Neurochem. 72:1707-1716.

14. Vavvas, D., et al. 1997. Contraction-induced changes in acetyl-CoA carboxylase and 5'-AMP-activated kinase in skeletal muscle. J. Biol. Chem. 272:13255-13261.

15. Musi, N., et al. 2001. AMP-activated protein kinase activity and glucose uptake in rat skeletal muscle. Am. J. Physiol. Endocrinol. Metab. 280:E677-E684.

16. Holzenberger, M., et al. 2000. Cre-mediated germline mosaicism: a method allowing rapid generation of several alleles of a target gene. Nucleic Acids Res. 28:E92.

17. Mu, J., Brozinick, J.T., Jr., Valladares, O., Bucan, M., and Birnbaum, M.J. 2001. A role for AMP-activated protein kinase in contraction- and hypoxia-regulated glucose transport in skeletal muscle. Mol. Cell. 7:1085-1094.

18. Burcelin, R., Crivelli, V., DaCosta, A., Roy-Tirelli, A., and Thorens, B. 2002. Heterogeneous metabolic adaptation of C57BL/6J mice to highfat diet. Am. J. Physiol. 282:E834-E842.

19. Burcelin, R., et al. 1995. Excessive glucose production, rather than insulin resistance, accounts for hyperglycaemia in recent-onset streptozotocin-diabetic rats. Diabetologia. 38:283-290.

20. Massillon, D., et al. 1995. Quantitation of hepatic glucose fluxes and pathways of hepatic glycogen synthesis in conscious mice. Am. J. Physiol. 269:E1037-E1043.

21. Flamez, D., et al. 1998. Mouse pancreatic beta-cells exhibit preserved glucose competence after disruption of the glucagon-like peptide-1 receptor gene. Diabetes. 47:646-652.

22. Koyama, K., et al. 1997. Beta-cell function in normal rats made chronically hyperleptinemic by adenovirus-leptin gene therapy. Diabetes. 46:1276-1280.

23. Zhou, Y.P., and Grill, V.E. 1994. Long-term exposure of rat pancreatic islets to fatty acids inhibits glucose-induced insulin secretion and biosynthesis through a glucose fatty acid cycle. J. Clin. Invest. 93:870-876.

24. Paolisso, G., et al. 1995. Opposite effects of short- and long-term fatty acid infusion on insulin secretion in healthy subjects. Diabetologia. 38:1295-1299.

25. Schuit, F.C., and Pipeleers, D.G. 1986. Differences in adrenergic recognition by pancreatic A and B cells. Science. 232:875-877.

26. McGarry, J.D. 2002. Banting lecture 2001: dysregulation of fatty acid metabolism in the etiology of type 2 diabetes. Diabetes. 51:7-18.

27. Kamohara, S., Burcelin, R., Halaas, J.L., Friedman, J.M., and Charron, M.J. 1997. Acute stimulation of glucose metabolism in mice by leptin treatment. Nature. 389:374-377.

28. Burcelin, R., Dolci, W., and Thorens, B. 2000. Portal glucose infusion in the mouse induces hypoglycemia. Evidence that the hepatoportal glucose sensor stimulates glucose utilization. Diabetes. 49:1635-1642.

29. Obici, S., et al. 2001. Central melanocortin receptors regulate insulin action. J. Clin. Invest. 108:1079-1085. doi:10.1172/JCI200112954.

30. Yoshimatsu, H., Oomura, Y., Katafuchi, T., Niijima, A., and Sato, A. 1985. Lesions of the ventromedial hypothalamic nucleus enhance sympathoadrenal function. Brain Res. 339:390-392.

31. Exton, J.H. 1980. Mechanisms involved in alpha-adrenergic phenomena: role of calcium ions in actions of catecholamines in liver and other tissues. Am. J. Physiol. 238:E3-E12.

32. Haynes, W.G., Morgan, D.A., Walsh, S.A., Mark, A.L., and Sivitz, W.I. 1997. Receptor-mediated regional sympathetic nerve activation by leptin. J. Clin. Invest. 100:270-278.

33. Nonogaki, K. 2000. New insights into sympathetic regulation of glucose and fat metabolism. Diabetologia. 43:533-549.

34. Marfaing, P., et al. 1991. Effects of counterregulatory hormones on insulin-induced glucose utilization by individual tissues in rats. Diabetes Metab. 17:55-60.

35. Chiasson, J.L., Shikama, H., Chu, D.T., and Exton, J.H. 1981. Inhibitory effect of epinephrine on insulin-stimulated glucose uptake by rat skeletal muscle. J. Clin. Invest. 68:706-713. 